\title{
Algunas consideraciones acerca de por qué el año que pareció el último de Franco en el poder no lo fue
}

\author{
Miguel Ángel Yuste de Paz *
}

\section{RESUMEN}

Al término de la /l Guerra mundial, Franco temió un pronto final para su régimen. En 1945, la derrota nazifascista empujo la reorganización de las Instituciones republicanas en el exilio, aunque nunca cuajaron como una alternativa sólida, ni entre los republicanos, ni entre las potencias democráticas. 1946 fue aun año de esperanzas para los antifranquistas. A pesar de las recomendaciones de las Naciones Unidas contra España en diciembre de 1946, el fenómeno de la Guerra fría que se hizo presente en 1947, ayudó decisivamente a la consolidación

de Franco.

Palabras clave: Fin de la II Guerra mundial, esperanzas, exilio republicano, Conferencias de San Francisco y Potsdam, Asamblea general de Naciones Unidas de diciembre de 1946, comunismo, Guerra fría, supervivencia.

\section{ABSTRACT}

At the end of the Second World War, Franco really feared they were the last days of his regime. In 1945 the nazifascist defeat pushed a reorganization of the Republicans Institutions in exile, but they never were an strong alternative, neither among the Republicans nor among the democratic powers. In 1946 the anti-Franco forces felt hopeful. In spite of the United Nations recommendations against Spain in December 1946, the reality of the Cold War phenomenon in 1947 was decisive for the survival of the Franco regime.

Key words: End of the Second World War, hopes, republican exile, San Francisco and Potsdam Conferences, United Nations General Assembly in December 1946, communism, Cold War, survival.

\footnotetext{
"Departamento de Historia Contemporánea, UNED.
} 


\section{ANTE EL MUNDO QUE SE AVECINABA}

Durante la segunda guerra mundial, aun a pesar de que España no estaba involucrada oficialmente en la contienda, las instituciones republicanas españolas en el exilio parecieron inexistentes e incapaces de establecer una relación fructífera con las potencias aliadas ante el horizonte de la posguerra, como hicieron las representaciones de otros países ocupados exiliadas en Londres. Bien es cierto que el gobierno en el exilio era una apariencia de lo que su nombre indicaba, y que las divisiones republicanas en la guerra civil habían continuado al salir de España sus dirigentes. Por esta razón, además de las evidentes dificultades de comunicación debidas a la propia dispersión del exilio, la reivindicación republicana careció de una representación capaz de hacerse oír de forma unitaria y convincente ante los gobiernos y los distintos foros internacionales de la época.

El dictador pasó por distintas posiciones a lo largo de la guerra mundial. De ofrecerse a luchar al lado de Hitler en los primeros momentos, a considerarse no beligerante mientras ayudaba a Alemania con los "Voluntarios" de la División Azul, hasta llegar a declarar la neutralidad de España cuando empezó a comprender que Alemania no iba a ganar. Por otro lado, miles de exiliados españoles combatieron al lado de los países aliados contra el nazismo. Estos dos hechos fueron dos bazas de las instituciones y los líderes republicanos en el exilio, quizás desaprovechadas para amarrar un compromiso aliado que les ayudase a acabar con el régimen de Franco en el futuro inmediato.

La nueva Europa devenía muy diferente a la que conocieron los republicanos cuando estaban en el poder. Entre los planes aliados no estaba continuar la liberación de Europa interviniendo en España. Aun teniendo en cuenta el panorama internacional tan diferente, si las potencias democráticas no habían ayudado decididamente a la República en la guerra civil española, ¿por qué lo habrían de hacer en aquellos momentos? La falta de compromiso de las democracias occidentales no era algo nuevo, ya venía prefigurada en la política de no intervención que desarrollaron en la guerra civil, que sirvió a Franco, apoyado por el Eje, a lograr la victoria ${ }^{1}$. A los dirigentes de la nueva gran potencia de la posguerra, Estados Unidos, no les gustaba el Caudillo, pero tampoco parecían dispuestos a intervenir en un pais que, por el momento, no perjudicaba sus intereses.

1 Richard Gillespıe, Historia del Partido Socialista Obrero Español, Alianza, Madrid, 1991, pág. 130. 
En marzo de 1945, en una carta al nuevo embajador en Madrid, Norman Armour, que fue convenientemente aireada por los republicanos españoles, el presidente Franklin D. Roosevelt, había condenado la existencia del régimen de Franco y de la Falange por su hostilidad a Estados Unidos y sus esfuerzos por propagar ideas fascistas, y había avisado: "Nuestra victoria sobre Alemania conllevará la exterminación del nazismo y similares ideologías" 2 . Un mes antes, las tres potencias participantes en la Conferencia de Yalta habian aprobado también la llamada «Declaración de la Europa liberada» 3 , que acordaba «...asistir a los pueblos liberados de la dominación nazi y de los estados satélites del antiguo Eje, en la resolución por medios democráticos de sus problemas políticos y económicos". Aunque no se mencionaba a España directamente, para muchos republicanos no dejaba de ser esperanzador, si bien, como recuerda Alberto J. Lleonart, fue, «otro alegato en el acervo documental de la cuestión española" 4 .

Franco, que recelaba de lo que se le podía venir encima, intentó una tímida aproximación al Reino Unido, y escribió a Churchill una carta que daba fe de su limitada y esquemática visión del mundo ${ }^{5}$. Le ofrecía la colaboración de España "para contrarrestar el poder de la URSS en una Europa donde Alemania estaba destrozada y Francia e Italia gravemente dañadas». En su contestación de enero de $1945^{6}$, Churchill le agradeció la ayuda prestada a los aliados al no oponerse a su desembarco en el norte de África en 1942, pero también le afeó la presencia alemana en España y la actuación de la División Azul en Rusia, que ponía en entredicho la cacareada neutralidad de España, sin dejar de recordarle, además, que Rusia era un aliado del Reino Unido en la guerra contra el Eje con el que estaba comprometido por los tratados anglo-soviéticos de 1942.

La carta de Churchill fue del agrado de Estados Unidos, que buscaba el apoyo británico a su política de presionar sobre el régimen español, evitando tener que llegar a la adopción de sanciones económicas contra él. Ambos países se mostraban de acuerdo en hacer lo posible por evitar

2 Carta de Roosevelt a Armour, 10-3-45, en: Spanish Information, Sep.-Oct. 1947, Archivo de la República española en el exilio, Fondo París, (ARE), 743.1, 1.3.2.

3 Declaración sobre la Europa liberada, 7-2-45, ARE, Ibídem.

4 A. J. LLEONART, Los origenes de la cuestión española en la II Guerra mundial, en Bulletin d'Histoire Contemporaine de l'Espagne, núm. 22, Centre National de la Recherche, Talence, 1995, pág. 75.

5 Cartas de Franco al Duque de Alba, embajador en Londres, y a Churchill, 18-10-44, National Archives, Washington, (NA), 741.52/1-1545, (15-1-45), 5987.

6 Réplica de Churchill,15-1-45, Ibidem. 
que tuvieran éxito las maniobras de Franco para enfrentarlos. Al Reino Unido le interesaba mantener sus lazos con España por consideraciones estratégicas, pero también porque en tiempos de paz iba a necesitar asegurarse suministros esenciales de distinto tipo, lo que no significaba que tuviera especial interés en conseguir una relación de cordialidad con su gobierno, mientras Franco y la Falange estuviesen en el poder. Los británicos pensaban que era el pueblo español quien debía decidir el régimen que tenía que sustituir a Franco, pero también eran conocedores de la falta de unidad de la oposición antifranquista. Algunas comunicaciones internas, sin embargo, no ocultaban el deseo del Foreign Office por ver un gobierno de tendencias moderadas en España.

\section{LAS NUEVAS BUENAS INTENCIONES DE TODOS}

Tras el final de la guerra en Europa y a escasos meses de la explosión de dos bombas atómicas en Japón, se trabajaba por hacer realidad una Carta de Naciones Unidas que fuese ratificada por los Estados miembros, que sirviese para el mantenimiento de la paz mundial, y que recogiese el respeto a los derechos del hombre y el de los pueblos a disponer de ellos mismos. La Conferencia de San Francisco fue la primera gran reunión internacional que trató la "cuestión española», también conocida como «problema español», y que aprobó, el 21 de junio de 1945, impedir la entrada de España a la Organización de Naciones Unidas, gracias a la labor de la dirección de la Junta Española de Liberación y a la ayuda, y voz inestimable, del gobierno de México.

La JEL habia nacido a finales de 1943 como un pacto para la restauración de la República entre PSOE, Izquierda Republicana, Unión Republicana, Esquerra Republicana de Catalunya, Acció Catalana Republicana, y apoyado por UGT y varias agrupaciones republicanas en diversos países, sin la participación de comunistas, socialistas «negrinistas", anarcosindicalistas, PNV y algún otro partido nacionalista catalán 7 . La Junta se proponía lograr que la República fuese reconocida como la alternativa legítima y democrática al régimen de Franco. Sin embargo, su manifiesta provisionalidad y la imposibilidad de obtener el reconocimiento buscado a corto plazo, le hizo transferir el importante capital político adquirido, sobre todo tras el éxito en San Francisco, al nuevo gobierno repu-

7 J. M. DEL VAlLe, Las instituciones de la República española en exilio, Ruedo Ibérico, París, 1976, pág. 75. 
blicano de José Giral, disolviéndose el 31 de agosto de 1945, a pesar de las protestas de líderes como el socialista Indalecio Prieto ${ }^{8}$.

La disolución de la JEL era consecuente con la opinión difundida tras la Conferencia de San Francisco, de potenciar un organismo representativo que pudiese recoger el reconocimiento diplomático de los miembros de las Naciones Unidas. La oposición antifranquista del interior de España era más bien escéptica respecto a la andadura emprendida por el gobierno; algunos creían incluso que su existencia torpedeaba la unidad de las fuerzas opositoras. Esta nueva, pero por otra parte, «tradicional» división, contribuía a alimentar el desconcierto de las diplomacias occidentales. Los británicos creían que los republicanos españoles en México habian perdido contacto con su país; que el nuevo gobierno no era representativo y que no sería sostenido por la oposición del interior en caso de que regresara a España ${ }^{9}$. El ministerio de Exteriores británico abogaba por no reconocer al gobierno Giral: "Mientras reconozcamos al gobierno de Madrid, no podemos oficialmente reconocer la existencia de un gobierno español en México» 10.

Entre el 17 de julio y el 2 de agosto de 1945 tuvo lugar la Conferencia de Potsdam, con la presencia de Stalin, Churchill, hasta su sustitución por el laborista y admirador de la causa republicana, Clement Attlee, y el nuevo presidente norteamericano, Truman. En la ciudad alemana se confirmó que el régimen vigente en España no podía ser admitido en la nueva sociedad internacional, como ya habían recomendado las Naciones Unidas:

Ninguna solicitud del presente gobierno español para formar parte de las organizaciones de las Naciones Unidas sería aceptada por haber sido fundado con el apoyo de los potencias del Eje ${ }^{11}$.

El acuerdo pudo haber sido mucho peor para Franco, pero Gran Bretaña hizo valer el principio de no intervención en los asuntos internos de otros paises ${ }^{12}$, temiendo que una intervención en España produjera una gran inestabilidad política que beneficiara a los soviéticos y perjudicara gravemente a sus intereses comerciales y estratégicos. Los británicos tuvieron el apoyo norteamericano. Stalin, que habia suscitado el tema, pro-

8 J. M. DEL VALLE, Las instituciones..., pág. 122.

9 Telegrama de la embajada francesa en Londres informando de la posición del $F$. O. sobre el nuevo gobierno republicano, AD/MAE, Z, 36, 6-9-45.

10 Estas frase aparecen en el dorso de una carpeta, sin firma, Public Record Office, Foreign Office Records, Londres, (FO)371-49556, Z 10910/18/41, 28-9-45.

11 Declaración de Potsdam, 2-8-45, en: op. cit., ARE 743.1., 1.3.2.

12 A. J. Lleonart, op. cit., pág. 76. 
puso que las Naciones Unidas aprobaran la ruptura con el régimen de Franco y la ayuda a las fuerzas democráticas. Tras laboriosas negociaciones, se llego a un acuerdo de mínimos entre los tres dirigentes y sus asesores 13 .

En Potsdam comenzó a desmoronarse el bloque aliado que había luchado contra Alemania. En el nuevo mapa internacional la Unión Soviética reivindicaba su propio área de influencia en el Este de Europa, y el problema de España, junto a otros, le podía ser útil como moneda de cambio para obtener sus deseos. Como recuerda el antiguo dirigente del PCE, Manuel Azcárate, en su obra Derrotas y Esperanzas:

De la reunión de Potsdam se desprendia claramente que el problema de España quedaba en manos del Reino Unido, Estados Unidos y, en todo caso, de Francia. Mal que nos pesase, la Unión Soviética se desentendía por voluntad propia 14

A pesar del rechazo, el dictador empezaba a ser consciente de la importancia estratégica y comercial de España para Occidente, y también de que podría aguantar mientras las potencias democráticas continuasen haciendo sólo declaraciones más o menos condenatorias contra él.

\section{CONDENAS, GESTOS}

El gran número de exiliados y la presión ejercida por los partidos de izquierda franceses solidarios con los republicanos españoles, hacían que el gobierno francés tuviese un gran interés en que se resolviera el problema español. En febrero de 1946, el ministro de Exteriores, Georges Bidault, le confesaba a su homólogo inglés, Ernest Bevin, que le resultaba muy difícil apaciguar a su opinión pública respecto al problema de España y que necesitaba realizar un gesto ante ellos ${ }^{15}$. El 26 de febrero Francia avisó de su intención de cerrar al tráfico la frontera con España el día 1 de marzo, en repulsa a las última ejecuciones del régimen. Esta medida buscaba también la adhesión de Gran Bretaña y Estados Unidos para romper

13 Enrique Moradiellos, La Conferencia de Potsdam de 1945 y el problema español, en: Tusell, Avilés, Pardo, Casanova, Mateos y otros, la Política exterior de España en el siglo XX, Congreso, UNED, Madrid, diciembre de 1997, págs. 308 y 316.

14 Manuel Azcarate, Derrotas y Esperanzas, La República, la Guerra Civil y la Resistencia, Tusquets, Barcelona, 1994, pág. 299.

15 Entrevista Bevin-Bidault en Londres, Archives Diplomatiques, Ministère des Affaires Étrangères, París, (AD/ MAE), Z, 67, 18-2-46. 
conjuntamente con España, pero no lo consiguió. A todo lo más que se llegó de forma conjunta, y a sugerencia norteamericana, fue a la publicación de una nota el 4 de marzo de $1946^{16}$, en la que se decía que era el pueblo español el que tenía toda la responsabilidad sobre su futuro y que recibiría el apoyo necesario, eso sí, cuando lograra liberarse del dictador:

No hay aquí intención de interferir en los asuntos internos de España. El pueblo español debe, por él mismo, labrar su propio destino (...)

Esperamos (...) el establecimiento de un gobierno interino bajo el que el pueblo español pude determinar libremente el tipo de gobierno que desea (...) Un gobierno interino recibiría el reconocimiento y apoyo de los pueblos amantes de la libertad.

La cuestión del mantenimiento o final de relaciones diplomáticas con el régimen actual en España (...) será decidida a la luz de los acontecimientos y teniendo en cuenta los esfuerzos del pueblo español en alcanzar su propia libertad.

Como gesto era significativo, y también valioso para el gobierno francés, pero para los republicanos españoles, cansados ya de los meros gestos, era otro más que se oponía a la existencia del régimen español, pero que para su desilusión y como nuevo aviso, obviaba a las instituciones republicanas y al nuevo gobierno constituido en México. La posición de las potencias ante las instituciones republicanas, a pesar de los importantes matices, no era ni mucho menos entusiasta. Mientras Bidault era partidario de reconocer semioficialmente a los representantes republicanos, pues la existencia de un gobierno en el exilio era una realidad, para Bevin aquello significaba asumir que el régimen que debía suceder al de Franco debía ser republicano. Bevin pensaba que los militares no elegirían la República si se les ponía en la tesitura de optar entre esta y Franco, por eso se preguntaba: “¿La monarquía no sería entonces la solución?" 17.

Uno puede imaginarse la desesperanza de los republicanos que esperaban una declaración que diese un ultimátum a Franco. Un experto en asuntos españoles de la embajada norteamericana en Londres, tras señalar que la declaración reforzaría al dictador, y que los gobiernos firmantes se habían visto casi obligados a ello para contentar a una opinión pública muy sensibilizada tras la ejecución, a finales de febrero, de diez guerrilleros capturados por la guardia civil, dejaba ver a su interlocutor británico:

Si no estamos preparados para intervenir activamente apoyando a los ele-

16 La declaración tranco-anglo-norteamericana, 5-3-1946, ARE 735.1, 1.13.2.

17 Informe sobre la entrevista entre Bidault y Bevin en Londres, AD/MAE, Z, 18-2-46. 
mentos de la oposición en España, no nos podemos permitir dar pasos precipitados para echar a Franco antes de que los propios españoles hayan tenido tiempo de dilucidar la mejor alternativa de gobierno.

Debemos, ingleses y americanos, tener el coraje de decir a nuestra opinión pública que no estamos preparados para acelerar la partida de Franco del poder, y que las sanciones económicas nos perjudicaran tanto como a los españoles, y que en efecto, no intentaremos hacer nada más... ${ }^{18}$.

Con todo, el gobierno francés no quedó satisfecho y propuso llevar el problema español ante el Consejo de Seguridad de las Naciones Unidas, sin hacer caso a las recomendaciones en sentido contrario. Los británicos se oponían porque no creían que la cuestión de España fuera un peligro para la paz internacional, y porque era esencialmente un asunto interno que no podía ser llevado al Consejo, que además podía crear peligrosos precedentes. Estados Unidos tampoco estaba de acuerdo en acudir al Consejo de Seguridad. Francia no se opuso a considerar otros métodos de presión decididos en común por las tres potencias y que no perjudicasen las necesidades vitales de la población, como pudiera ser la interrupción se suministros que permitian a España subsistir.

El 17 de abril, el caso de España empezó a discutirse en el Consejo de Seguridad por mediación del delegado polaco, y el 29 se creó un subcomité para que determinara si la situación española amenazaba la paz y seguridad internacional. El 1 de junio, el subcomité concluyó que aunque no era una amenaza para la paz y la seguridad internacional si que lo era potencial, por lo que el Consejo de Seguridad, adoptando los principios contenidos en la nota tripartita de 4 de marzo de 1946, recomendó llevar el caso a la Asamblea general para que los países miembros rompiesen sus relaciones diplomáticas con España 19.

Francia también temía quedar relegada en caso de llevarse a cabo una transición a la monarquía que Gran Bretaña apoyaba y por la que trabajaba. Esta era la preocupación que transmitía a su gobierno el embajador francés en España, a finales de $1945^{20}$. Si los hombres con los que los servicios diplomáticos británicos mantenian contacto entonces,

18 Conversación del F. O. con Mr. George, de la embajada USA, FO371- 60352, Z-2193, 4-3-46.

19 El desarrollo de la propuesta trancesa con las respectivas contrapropuestas británicas, estadounidenses, y de nuevo francesas, hasta que es introducida en el Consejo de Seguridad, a propuesta polaca, y que culmina en la recomendación hecha por el Consejo a la Asamblea General de la ONU, se puede seguir en la volúmenes de documentos Foreign Relations United States, (FRUS), Vol. V, 1946, págs. 1055 a 1075.

20 Comunicado del cónsul francés en Barcelona a Bidault, tras la visita del embajador británico a la ciudad, AD/MAE, Z, 65, 26-11-45. 
eran los que luego iban a dirigir el pais, era evidente que Gran Bretaña obtendría importantes ventajas con el nuevo régimen, mientras que aquellos recordarían a Francia: "por su apoyo a una banda de republicanos desacreditados y por tratar de conducir a España a las peores aventuras». Pero Franco estaba al corriente de las maniobras británicas y no dudó, cuando lo creyó oportuno, en castigar de forma ejemplar a los monárquicos más señalados ${ }^{21}$.

A finales de 1945, el Foreign Office creía que el relevo de Franco era inminente y que, por tanto, habia que cambiar de rumbo e ir hacia una política de apoyo activo a un acuerdo entre monárquicos y republicanos, sin dejar de sopesar el peligro de despertar una reacción indeseada en los militares españoles ante lo que verían como una intolerable injerencia extranjera 22. Ingleses y norteamericanos trataron de influir en algunos importantes miembros del Ejército para que aceptasen el acuerdo. Estados Unidos incluso sugirió que los embajadores de las tres potencias occidentales se reunieran con el ministro de exteriores y el jefe del Ejército español para convencerles de que había llegado el momento de que el régimen de Franco finalizara.

\section{«KEEP THE BALL ROLLING» *}

A finales de 1945, el departamento de Estado norteamericano no disponía aun de una opinión definida sobre la política a seguir con España. El subsecretario de Estado, Miller, era partidario de dar algún tipo de reconocimiento al gobierno republicano exiliado en México, en vista de que fue una vez el gobierno legal de España, sin que ello implicase reconocer una legitimidad actual, y se mostraba de acuerdo con la sugerencia de Culbertson, jefe de Europa occidental del mismo Departamento, de dejar las cosas como estaban si no había seguridad de evitar un totalitarismo de izquierdas en España, aceptando «keep the ball rolling» 23 con lo propuesto y aceptado por Estados Unidos en San Francisco y Potsdam. Mi-

21 Florentino PORTERo, Franco aislado, La cuestión española 1945-1950, Aguilar, Madrid, 1989, pág. 62.

22 Minuta a una carta del embajador británico en Madrid al F. O., (1-12-45), FO371-49629, 512-45.

23 El memorándum del subsecretario de Estado definía la posición de Estados Unidos respecto a España, que era, a finales de 1945, esperar a los acontecimientos. Destaca también que, y aunque ya en San Francisco y Potsdam se habían concertado posiciones respecto a España, se valoraban las consultas directas con la Unión Soviética, aunque fuese con el fin de evitar que 
ller también pensaba que podía ser útil consultar con los soviéticos los pasos a seguir respecto a España, para evitar su veto a un posible gobierno alternativo a Franco apoyado por Estados Unidos.

Como es de imaginar, los soviéticos tenían su propia visión del problema y sus propios planes. Precisamente, el conocimiento de esos planes sería decisivo para que las potencias occidentales enfrentaran el asunto de España desde una óptica que, aunque no era nueva, no se había impuesto como la imperante todavía. El informe del encargado de Negocios de Estados Unidos en Moscú, George Kennan, fechado el 3 de febrero de 1946 , es un valioso antecedente documental que nos sitúa en lo que sería el campo de batalla de la guerra fría ${ }^{24}$. El informe analizaba las causas del interés soviético por España. Para la Unión Soviética, España era unos de los pocos países occidentales donde podría triunfar una revolución, dada la similitud de las condiciones de pobreza con las existentes en la Rusia prerrevolucionaria. España era, además, una espina duramente clavada en el orgullo ruso por varios motivos: el fracaso de los republicanos en la guerra civil a pesar de la ayuda soviética, si bien Stalin no se volcó en el envío de armas en la cantidad y la calidad suficiente que la República española le había solicitado; y el nefasto recuerdo dejado por la División Azul, que luchó junto a los nazis en suelo ruso. Rusia también concedía a España una alto valor estratégico por su posición geográfica y su alto valor político como puente a Hispanoamérica y Marruecos. Para Kennan, la URSS, consciente de su impopularidad, descartaba una intervención militar en España, pero buscaba movilizar a la opinión pública occidental para que empujase a sus respectivos gobiernos a tomar medidas contra Franco. Ciertamente, y como temían Miller y Culbertson, los rusos recelaban de un posible gobierno moderado democrático y en buena sintonía con los países occidentales, y por eso arremetían contra los que consideraba muñidores de un acuerdo amplio entre las fuerzas antifranquistas: Prieto, Maura o D. Juan. Como confesaba un interlocutor soviético a un miembro de la embajada británica en Moscú, Rusia necesitaba de la inestabilidad política de España para sacar adelante sus planes ${ }^{25}$. Aunque Kennan dudaba de que Moscú fuese capaz de liderar un cambio en España dado el diferente carácter de los dos pue-

vetase un gobierno alternativo a Franco si lo apoyaba Estados Unidos. Memorándum del subsecretario de Estado, Miller, para Culbertson, NA 711.52/11-2045, 59, 3327.

24 Memorándum secreto del Encargado de los asuntos norteamericanos en Moscú, George F. Kennan para el secretario de Estado, FRUS, vol. V, 1946, 752.61/2-346, págs. 1033-1036.

25 El ruso Maisky, opinaba ante el británico Roberts, que los ingleses eran: " too cautious and that a small civil war in Spain would do no harm.", Embajada británica en Moscú para el Foreign Office, FO371-60441A, Z3091, 2-3-46. 
blos, su informe fue apoyado y ampliado por el encargado de negocios en Madrid, Butterworth 26.

El Foreign Office se mostró, en general, de acuerdo con los puntos del informe, y recordó que el resultado del acuerdo de Potsdam fue una notable victoria para la URSS y su política de penetración en España 27 . Pero también temía que si la Unión Soviética entraba decididamente a influir en la política española, y como consecuencia, rebrotaba la guerra civil, el Reino Unido entraría en guerra con la URSS ${ }^{28}$. Era un asunto que no había escapado al análisis de Butterworth del informe de Kennan: el choque de intereses entre Gran Bretaña y la URSS que podía producirse en el Mediterráneo.

En la clase política norteamericana estaban los que querian dejar pasar el tiempo, como ya hemos visto, y quienes eran partidarios de intervenir decididamente, si bien estos ya en retroceso. Era comúnmente aceptado que los dirigentes republicanos iban a ser incapaces de ejercer el poder por mucho tiempo en España, pero también se dudaba de que la restauración monárquica fuera a tener éxito si no contaba con los elementos liberales del ejército.

En marzo de 1946, la actitud norteamericana respecto a España estaba todavia muy vinculada a Gran Bretaña, aunque muy pronto, la creciente presencia internacional de la Unión Soviética introduciría un cambio fundamental en éste y en otros importantes asuntos del panorama internacional. El departamento de Estado norteamericano reconocia la poca efectividad de lo realizado hasta el momento, pero también la dificultad de involucrarse en un cambio político en España sino se estaba dispuesto a intervenir recurriendo, si era necesario, al ejército para evitar el previsible caos. Respecto a la alternativa que representaba el gobierno republicano como recambio a Franco, para los norteamericanos era impensable que los militares accedieran a un cambio donde el gobierno Giral fuese protagonista. Además, como recogia un análisis que manejaba el Departamento de Estado: «El ideal republicano no está muerto, pero el grupo de Giral, como individuos, tienen pocos seguidores en España» 29. El Departamento de Estado proponía mantener las relaciones diplomáticas con España, pero aislando internacionalmente a su régimen; contrarrestar la propaganda soviética en favor de la violencia revolucionaria, asegurando

\footnotetext{
26 Butterworth para el secretario de Estado, NA 852.00/2-1546, 59, 6337.

27 FO371- 60441A, 9-2-46.

28 Informe del general Ismay para Attlee, citado en: Florentino Portero, op. cit., pág. 148.

Memorandum on Policy towards Spain, NA 711.52/7-1846, 59, 3327, pág. 1.
} 
a los españoles que una solución moderada que diese paso a la libertad política tendría todo el apoyo norteamericano, y también, arruinar la propaganda de Franco de que la única alternativa a él era el comunismo ${ }^{30}$.

Curiosamente, la URSS no reconoció al gobierno republicano. El ministro de exteriores, Molotov, le hizo saber a Giral que: «Las condiciones políticas, militares, diplomáticas y psicológicas que existían en el mundo de los trabajadores, no permitían a la URSS acoger (dicha) pretensión» 31 .

\section{LO QUE PARECIÓ QUE IBA A SUCEDER}

Aunque es constatable que a lo largo de la historia de las relaciones internacionales los intereses particulares de los países han hecho aliados antagónicos en lo ideológico o en lo personal incluso, la barbarie reciente del nazismo y el fascismo en Europa, había convertido casi en certeza para los españoles, antifranquistas o no, la imposibilidad de pervivencia en Europa de un régimen tan estrechamente ligado a aquellos, y por ello la confianza en que los llamamientos a la solidaridad democrática de los republicanos iban a encontrar la respuesta esperada. No es de extrañar pues, que ese momento de la Historia, pareció el de la desaparición del régimen de Franco.

Aquel ideai casi romántico que se había propagado como el triunfo de la libertad en la II Guerra mundial, suponía ciertamente una lectura parcial y un tanto irreal, pues a los gobiernos vencedores no les iba a importar que en algunas de las regiones periféricas, como España, no hubiera sociedades equiparables a las de la región central donde se encontraban Francia, Gran Bretaña, Italia y Alemania, fronteriza con la zona oriental dominada por la Unión Soviética, y que debía ser el escaparate ideal de la democracia occidental. Muchos ciudadanos de toda Europa habian creido en que se materializaría en todo el Contienente, pero algunos se empezaban a dar cuenta ya de que el nuevo orden internacional iba a impedir que fuera así, al menos en el sur y en el este.

El líder socialista Indalecio Prieto, que para el Foreign Office era el único dirigente del exilio republicano con predicamento en España ${ }^{32}$, era

30 Ibídem, págs. 10 y 11.

31 Telegrama de la embajada francesa en Madrid sobre la entrevista de Molotov y Giral en París, AD/MAE, Z, 40, 19-10-46. 
consciente del derrotero que estaban tomando los acontecimientos y se dirigió al Primer ministro británico, Clement Attlee, tras la decisión del Consejo de Seguridad, el 26 de junio, de mantener la cuestión española bajo vigilancia. Le advertía de la contradicción existente en la política de las potencias occidentales, que por un lado abogaban por la no intervención en España, mientras por el otro seguian manteniendo relaciones diplomáticas con Franco. Esto colocaría a la Unión Soviética como única valedora de la restauración de la República, lo que haría crecer las simpatías hacia los soviéticos entre la izquierda no comunista española. Para Prieto era necesaria la celebración de elecciones libres con el fin de neutralizar los progresos comunistas. Mientras tanto, propugnaba una total obediencia del exilio a las decisiones de los partidos y sindicatos del interior, y añadía, dirigiéndose a los socialistas:

Si las instituciones republicanas habian perdido su vitalidad al mismo tiempo que en el ámbito nacional o internacional había aparecido otra solución con posibilidades de lograr la restauración de la República, debemos servir dicha opción. Si la opción es honorable debemos elegir libremente, pero si la rigidez de nuestras funciones nos impide su aceptación, nuestros representantes en el gobierno deben advertir que nadie les puede acusar de deslealtad si ellos obedecen dicha opción, el mandato viene del partido socialista en España 33.

El congreso que los socialistas celebraron en Toulouse a finales de mayo de 1946, admitió la posibilidad de que Franco fuese sustituido por un gobierno de centro, incluso por una monarquía, confiando en que el resultado de un plebiscito posterior inclinaría al gobierno a la izquierda 34 .

La esperanza de que finalmente el mundo se volcase contra Franco era un sentimiento compartido por miles de republicanos españoles. La propaganda era un arma necesaria para explicar a la sociedad internacional las reivindicaciones de las instituciones republicanas en el exilio. En ella se volcaban desde políticos a voluntarios abnegados, españoles o no, que trataban, generalmente con escasos medios, de influir en la opinión pública, pero también en la clase política de los paises en los que estaban radicados. En 1946, varios países habían reconocido ya al gobierno Giral y roto con Franco, y aunque ciertamente no eran muchos, había otros muchos que estaban esperando el resultado de las re-

32 Minuta del F. O. sobre una carta para el Secretario sobre I. Prieto, FO371-60334, Z2891, 23-3-46.

33 Carta de Prieto a Attlee, 27-6-46, FO371-60335, Z6491, 27-6-46/1-8-46; AD/MAE, Z, 39, 27-6-46. 8-46.

34 Minuta de Hoyer Millar sobre la carta de Prieto a Attlee, FO371-60335, Z 6491, 27-6-46/1- 
soluciones que tomara la Asamblea general de las Naciones Unidas para hacerlo.

\section{RECOMENDACIONES CONTRA FRANCO}

En la sesión de apertura del 24 de octubre, el secretario general de la ONU, Trygve Lie, mencionó la existencia de un régimen fascista en España sin estar en el orden del día. Giral por su parte, había logrado del ministro de exteriores ruso, Molotov, la retirada del veto soviético a que la cuestión española se discutiese en la Asamblea. Entre la oposición antifranquista existía un sentimiento generalizado de que el resultado de la Asamblea general de las Naciones Unidas era la última oportunidad para lograr una intervención en España. Es lo que reflejan los personajes de la obra de Juan Hermanos, seudónimo de un autor desconocido que, mezclando ficción y realidad, nos muestra como se vivió este acontecimiento en el Madrid de aquellos dias:

No se nos ocultaba que sólo teníamos una probabilidad contra diez de triunfar, pero hubiera sido un crimen no intentar nada. Si la ONU se limitaba a una declaración de principios sin intimidación....jpero no podíamos admitir tal hipótesis! 35.

Giral y De los Ríos se trasladaron a Nueva York donde desplegaron una intensa actividad. Giral entregó a los delegados un documento, complementario del editado en mayo para el Consejo de Seguridad, donde se exponía la opinión razonada del gobierno republicano respecto a las medidas que la Asamblea General de la ONU debía tomar contra Fran$c 0, y$ el por qué de éstas ${ }^{36}$. El asunto de España se empezó a discutir en el Comité político y de seguridad. Tras la intervención del delegado polaco en la que se mostraba favorable a la ruptura con España, que fue secundado por Venezuela, intervino el senador norteamericano Connally. Éste presentó un proyecto que insistía en la postura ya conocida de evitar que España participara en los organismos internacionales, y que invitaba al pueblo español a restablecer la legitimidad para que España pudiese formar parte de las Naciones Unidas. Gran Bretaña mostró su apoyo al proyecto de Connally, mientras que Francia y la URSS apoyaron

35 Juan Heamanos, El fin de la esperanza, Testimonio, Tecnos, Madrid, 1998, pág. 152.

36 Posición del gobierno de la República española ante la Asamblea General de las Nacionos Unidas a colebrar en Nueva York el mes de octubre de 1946, ARE, 712.3., 2.1.1., octubre de 1946. 
la propuesta polaca. También México se mostró favorable a la ruptura y a que se determinase alguna forma de intervención. El Comité aprobó crear una subcomité que acordara la decisión a tomar. Su primera resolución fue aprobada por el Comité el 9 de diciembre y finalmente por la Asamblea General el día 12, por mayoría de dos tercios, con el voto favorable de 34 delegaciones, seis en contra y 13 abstenciones ${ }^{37}$. Era una resolución que recomendaba impedir al gobierno franquista adherirse a las instituciones internacionales de las Naciones Unidas. Pero lo más trascendente era que también recomendaba a los países miembros que retirasen de Madrid a los embajadores y ministros plenipotenciarios allí acreditados 38 .

Se había esperado una resolución más contundente y dura. Bien es cierto que las Naciones Unidas como organismo no podían mucho más allá si las potencias no querían, ni siquiera asegurar el cumplimiento de lo aprobado. Estados Unidos y Gran Bretaña habían aceptado un texto que en un principio no apoyaban, pero que al menos les libraba de tomar medidas no deseadas y arriesgadas para sus intereses. Retirar a los embajadores no era lo mismo que romper relaciones diplomáticas, aunque era lo suficientemente importante para preocupar y soliviantar al régimen, que no tardó en movilizarse y disfrazarlo de afrenta internacional incompatible con el «orgullo español».

Giral quiso, a pesar de todo, resaltar lo conseguido. El trabajo que había realizado en diversos frentes diplomáticos habia sido arduo y también provechoso. Sin embargo, el contenido final de la resolución, que en los primeros momentos de la posguerra mundial hubiera sido muy importante, a aquellas alturas no colmaba las expectativas despertadas. Volviendo a Juan Hermanos:

La radio daba las noticias en inglés.(...)Las noticias se sucedían. No se hablaba de España. Los otros se impacientaban. (...) Yo pensaba: «Si se hubiera decidido algo ya lo hubieran dicho. Quieren ahogar el asunto." Miguel levantó los ojos y me miró. (...)

Habíamos perdido. Aquello estaba terminado.

Deprisa los lápices. Escribir, escribir... Los embajadores... Proposiciones... ¡Uf!... Aquello estaba terminado ${ }^{39}$.

37 Releases to the United Nations Delegates, Spanish Information, ARE, 15.7, 1.12.4.,1-1-47.

38 En: The world against Franco, Spanish Information, septiembre-octubre 1947, ARE, 743.1.,1.3.2.; Lleonart A. J., CastieLA F. M.^, op. cit., págs. 386-389. 
El gobierno republicano veía resignado que al igual que la Nota tripartita y la Declaración de Potsdam, la resolución aprobada tampoco mencionaba a las instituciones republicanas en el exilio, ni como alternativa al régimen que se condenaba, ni tan siquiera haciéndose eco de su existencia, y eso a pesar de que sus representantes habían estado presentes en Nueva York a invitación del secretario general, y de haber oído su quejas y leído sus informes. Los socialistas aprovecharon la declaración de la ONU para apelar a la búsqueda de la unidad de acción de todas las fuerzas antifranquistas, saltando por encima o por los lados del gobierno del exilio, y para ello no se olvidaron del párrafo en el que la Asamblea:

Recomienda que, si en un plazo razonable, no se ha establecido un gobierno que tenga su autoridad del consentimiento de los ciudadanos, que se comprometa a respetar la libertad de palabra, de cultos y de reunión, y a organizar sin dilación unas elecciones por las cuales el pueblo español, liberado de toda coacción o intimidación, y sin consideración de partidos, pueda expresar su voluntad, el Consejo de Seguridad estudie las medidas adecuadas a tomar para remediar esta situación ${ }^{40}$.

La existencia de las instituciones republicanas tras la resolución de la ONU quedaba ahora en entredichn. El 17 de diciembre, Prieto aprovechó para atacar con dureza a Giral con el argumento de que su gobierno no tenía ninguna posibilidad de establecerse en España. Consecuentemente, pidió a su partido que se retirara del mismo. El 21 de enero, socialistas y anarcosindicalistas acordaran la dimisión de sus ministros. Al día siguiente, y tras varios intentos por seguir, Giral se vería abocado a la dimisión.

\section{EL INICIO DE LA GUERRA FRIAA ALIVIA A FRANCO}

Los relaciones de Francia, Gran Bretaña y Estados Unidos con España habían sido, en cada caso, fruto de la historia, de las características eventuales de sus gobiernos y de los variados intereses de cada uno, pero la existencia de la dictadura de Franco y la estrecha colaboración de los tres países en la II Guerra mundial, introdujo elementos comunes que hicieron que muchas iniciativas individuales fueran, al menos, consultadas entre ellos, lo que contribuyó a frenar acciones unilaterales más osadas, al menos hasta que a finales de 1947, Estados Unidos dio muestras de que iba a ejercer su liderazgo mundial de forma activa, imponiendo su concepción de lo que debía ser el nuevo orden europeo. Los intentos de británicos y fran-

39 Juan Hermanos, op. cit., págs. 152-153.

40 Lleonart, A. J., Castiella, F. M.", op. cit., pág. 388. 
ceses por seguir manteniendo un status de grandes potencias fueron chocando, una y otra vez, con la realidad de su nueva dimensión internacional que la II Guerra mundial les había dejado. No existía ya una potencia europea que pudiera imponerse en el continente sin contar con Estados Unidos. La confirmación de la nueva situación que vivía ya el mundo ocurrió a raíz de la guerra civil que se vivia en Grecia desde octubre de 1946.

Las graves dificultades económicas del gobierno británico le obligaron a dejar de prestar ayuda al gobierno griego en su lucha contra los rebeldes comunistas, y a solicitar a Estados Unidos que le sustituyese en el empeño. El 12 de marzo, el presidente Truman se dirigió al Congreso norteamericano solicitando fondos para continuar dicha ayuda, pero que representaba algo mucho más importante que una mera solicitud para sostener al gobierno griego ${ }^{41}$. Para Truman Estados Unidos debia asumir el liderazgo de los llamados «paises libres" y contener el avance soviético en Europa y en el mundo. El discurso del presidente norteamericano, que sería conocido como Doctrina Truman, se convirtió en esquema fundamental de la política exterior occidental durante la Guerra Fría 42.

Con la consolidación del anticomunismo como eje de la política exterior norteamericana y occidental, Franco iba a tener mucho menos de que preocuparse. Ahora podia decir que existía una fundamental coincidencia con la nueva potencia mundial. El dictador pasó, en pocos meses, del disgusto por la condena de las Naciones Unidas a un cierto optimismo por el contenido del discurso de Truman. Para un régimen que tanto había temido por su futuro con el triunfo de las democracias y la propia anomalía de su existencia en la Europa de la posguerra mundial era una buena noticia. Los serias amenazas internacionales que la dictadura franquista sufrió en 1946 parecian alejarse para siempre.

Este optimismo se verá confirmado en octubre de 1947 con el documento aprobado por el departamento de Estado norteamericano, conocido como informe Kennan y que, en esencia, propugnaba la normalización de las relaciones de Estados Unidos con España 43.

41 Charles ZoRgBiBe, Chronologie des relations internationales depuis 1945, Presses Universitaires de France, París, 1991, pág. 27.

42 Florentino Portero, Franco aislado..., pág. 221.

43 Informe titulado: U. S. Policy towards Spain, de George F. Kennan, (Policy Planning Staff) para el secretario y subsecretario de Estado norteamericano, 24-10-47, FRUS, vol. III, 1947, $711.52 / 10-2847$, págs. 1091 a 1095. 